\title{
Energy crop mapping with enhanced TM/MODIS time series in the BCAP agricultural lands
}

Cuizhen Wang, Dept. of Geography, University of South Carolina, Columbia, SC 29208; cwang@mailbox.sc.edu

Qian Fan, Dept. of Geography, University of South Carolina; fanq@email.sc.edu

Qingting Li, Institute of Remote sensing and Digital Earth, Chinese Academy of Sciences, Beijing 100094, China; liqt@radi.ac.cn

William M. SooHoo, Dept. of Geography, University of South Carolina; wsoohoo@email.sc.edu Linlin Lu, Institute of Remote sensing and Digital Earth, Chinese Academy of Sciences, Beijing 100094, China; lull@ radi.ac.cn

\begin{abstract}
Since the mid-2000s, agricultural lands in the United States have been undergoing rapid change to meet the increasing bioenergy demand. In 2009 the USDA Biomass Crop Assistance Program (BCAP) was established. In its Project Area 1, land owners are financially supported to grow perennial prairie grasses (switchgrass) in their row-crop lands. To promote the program, this study tested the feasibility of biomass crop mapping based on unique timings of crop development. With a previously published data fusion algorithm - the Enhanced Spatial and Temporal Adaptive Reflectance Fusion Model (ESTARFM), a 10-day normalized difference vegetation index (NDVI) time series in 2007 was established by fusing MODIS reflectance into TM image series. Two critical dates - peak growing (PG) and peak drying (PD) - were extracted and a unique "PG-0-PD" timing sequence was defined for each crop. With a knowledge-based decision tree approach, the classification of enhanced TM/MODIS time series reached an overall accuracy of $76 \%$ against the USDA Crop Data layer (CDL). Especially, our results showed that winter wheat single cropping and wheat-soybean double cropping were much better classified, which may provide supplementary data for the CDL product. More importantly, this study extracted the first spatial layer of warm-season prairie grasses that have not been published in any national land cover products, which could serve as a base map for decision making of bioenergy land use in BCAP land.
\end{abstract}

Keywords: BCAP; time series analysis; ESTARFM; bioenergy; native prairie grass 


\section{Introduction}

Bioenergy production today has an increasing impact on agricultural land use change in the United States (Farrell et al. 2006; Wallander et al. 2011). As corn grain remains the primary feedstock for domestic biofuel, corn planting areas are dramatically expanded, reaching a historical record (after 1944) of 93.6 million acres in 2007 (Dougherty and Geuder 2008) and the $2^{\text {nd }}$ highest of 92.2 million acres in 2011 (Schill 2011). Meanwhile, perennial prairie grasses are dedicated as one of the alternative energy crops to leverage the corn-dominated bioenergy production, food security and environment conservation. Switchgrass (Panicum virgatum L.), a native prairie grass in the U.S. Midwest, was identified by Department of Energy (DOE) as a model cellulosic energy crop in early 1990s. Since then, adaptation of native prairie grasses to poor soil conditions has led researchers to examine its competitive feedstock potentials and positive environmental implications on highly erodible and environmentally sensitive lands (Kort et al. 1998; McLaughlin et al. 2002; McLaughlin and Kszos 2005).

In 2009, the United States Department of Agriculture (USDA) established the Biomass Crop Assistance Program (BCAP) to promote cultivating perennial energy crops in a conservative manner (http://sustainableagriculture.net). Current extents of bioenergy land use in these BCAP lands are poorly recorded. From 1970s, the USDA/NASS Cropland Data Layers (CDL) have been annually published in selected states and covered the conterminous U.S. after 2009 (NASS 2010). The CDL maps are classified from multi-temporal, 30-56m satellite images assisted with intensive ground truthing data, reaching $80-90 \%$ overall classification accuracies in major agricultural regions (Allen et al. 2002; Boryan et al. 2011). Perennial energy crops, i.e. warmseason prairie grasses, have not been classified in any published land cover products. Grasslands 
and pasturelands are usually less managed, with a mixture of grass species growing in field. Their spectral features are more complicated than monoculture of annual crops. Although prairie grasses have later growth and shorter growing season than cool-season forage grasses (Wang et al. 2011, 2013), they are difficult to delineate from limited scenes of satellite imagery used for current products such as CDL and National Land cover Dataset (Xian et al. 2009).

Satellite image series repetitively acquired in a growing season reveal land surface phenology and thus enhance crop mapping. At kilometer scales, crop phenology could be extracted from frequently observed imagery such as the Moderate Resolution Imaging Spectroradiometer (MODIS) products (Wang et al. 2011). For each crop, its unique phenological features provide important information for crop delineation (Zhong et al. 2015). However, crop phenology is often strongly affected by geographically varying crop calendars and cropping managements. Weather dynamics also alter the timing of crop's phenological events in different years (Yuan et al. 2015). These limitations, as well as the mixed crop fields in a coarse-resolution pixel, dramatically affect the accuracies of regional crop mapping (Wang et al. 2015).

Frequent satellite observations at medium resolutions are not available due to long re-visit cycles (e.g., 16 days for Landsat) and frequent cloud covers in growing seasons (Xian et al. 2009). In recent years, great efforts have been made to disaggregate coarse-resolution data to match those from different sensors and therefore, to generate medium-resolution satellite time series. Roy et al. (2008) developed a semi-physical fusion model to predict the direction-corrected Landsat-like reflectance by counting into the sun-target-sensor geometry in the MODIS albedo product. Assisted with high-resolution land use database, a linear mixed model was used to predict 
Landsat-like image from the Medium Resolution Imaging Spectrometer (MERIS) (Zurita-Milla et al. 2009). Gao et al. (2006) was among the first efforts to fuse MODIS and Landsat Thematic Mapper (TM) data for predicting surface reflectance at spatial resolution of TM and temporal frequency of MODIS in a spatial-temporal adaptive reflectance fusion model (STARFM). Hilker et al. (2009) modified it into a Spatial Temporal Adaptive Algorithm for mapping Reflectance Change (STAARCH) model to take into account disturbance events not recorded in the base image. Weng et al. (2014) applied the STARFM in thermal region to generate land surface temperature datasets by considering annual temperature cycle in TM/MODIS fusion. In agricultural lands, spectral dynamics in both spatial and temporal dimensions should be considered in pixel disaggregation. Zhu et al. (2010) developed an Enhanced STARFM (ESTARFM) to preserve spatial details in heterogeneous landscapes along with temporal changes between two images. It may effectively preserve the field-level spatio-temporal dynamics of crop development.

This study adopts the ESTARFM algorithm to extract an enhanced TM/MODIS image series in 2007. With the Normalized Difference Vegetation Index (NDVI) time series, critical timings of crop development are extracted. A derivative-based decision tree is then developed to delineate perennial energy crops (warm-season prairie grass) from annual crops in the BCAP land, southwestern Missouri. This experimental study testes the feasibility of spatially and temporally enhanced satellite time series for regional bioenergy land use monitoring.

\section{Materials and Methods}

\subsection{Study Area and Data Sets}


The BCAP Project Area 1 is composed of 39 counties in western Missouri with a few in Kansas (Fig.1). It targets the 20,000 acres of new biomass cropland, complementing the existing 20,000 acres, to plant switchgrass and other native grasses such as big bluestem, indiangrass and Virginia wildrye (FSA 2011). Our study area in this experiment is the south end of this BCAP land, covering four counties from south to north: Barton, Vernon, St. Clair, and part of Bates (Fig.1). Pasturelands dominate the area. Annual crops are primarily corn, soybean and winter wheat. Both winter wheat single cropping and wheat-soybean double cropping are common in the Midwest.

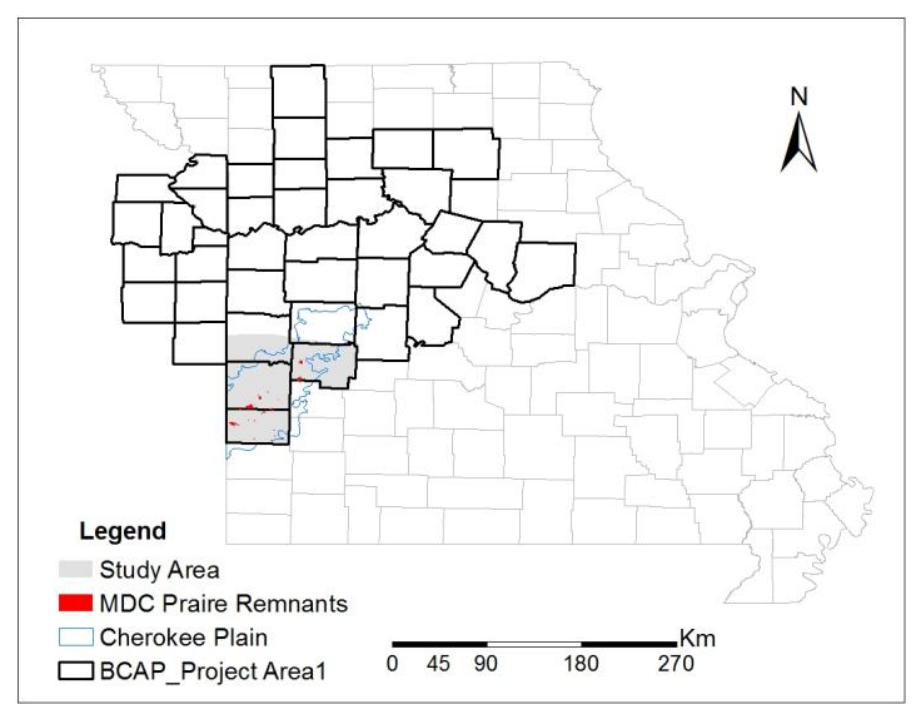

Figure 1 The BCAP land and our study area. The prairie remnants in the Cherokee Plain, managed by Missouri Department of Conservation (MDC), were published in Wang et al. 2010.

Table 1 The TM/MODIS time series collected in this study. Note the date of each MODIS image actually represents an 8-day temporal length.

\begin{tabular}{r|c|l|r|c|l}
\hline \multicolumn{1}{c|}{ Date } & DOY & Image & \multicolumn{1}{c|}{ Date } & DOY & Image \\
\hline $2 / 26 / 2006$ & 057 & TM & $7 / 7 / 2007$ & 188 & TM \\
\hline $3 / 6 / 2007$ & 065 & MODIS & $7 / 20 / 2007$ & 201 & MODIS \\
\hline $3 / 14 / 2006$ & 073 & TM & $8 / 5 / 2006$ & 217 & TM \\
\hline
\end{tabular}




\begin{tabular}{r|l|l|r|l|l}
\hline $4 / 2 / 2007$ & 092 & TM & $8 / 8 / 2007$ & 220 & TM \\
\hline $4 / 7 / 2007$ & 097 & MODIS & $8 / 21 / 2008$ & 233 & TM \\
\hline $4 / 18 / 2007$ & 108 & TM & $9 / 6 / 2006$ & 249 & TM \\
\hline $4 / 23 / 2007$ & 113 & MODIS & $9 / 14 / 2007$ & 257 & MODIS \\
\hline $5 / 9 / 2007$ & 129 & MODIS & $9 / 22 / 2007$ & 265 & MODIS \\
\hline $5 / 20 / 2007$ & 140 & TM & $9 / 29 / 2008$ & 271 & TM \\
\hline $5 / 25 / 2007$ & 145 & MODIS & $10 / 8 / 2008$ & 281 & TM \\
\hline $6 / 2 / 2006$ & 153 & TM & $10 / 24 / 2006$ & 297 & TM \\
\hline $6 / 10 / 2007$ & 161 & MODIS & $10 / 30 / 2008$ & 303 & TM \\
\hline $6 / 21 / 2007$ & 172 & TM & $11 / 9 / 2006$ & 313 & TM \\
\hline
\end{tabular}

The study area is covered in one Landsat tile (path 26/row 34). Table1 lists the 17 cloud-free Landsat5 TM scenes available from February to November. Primary data sets are in 2007. For scenes with high cloud cover, those acquired at similar dates in 2006 and 2008 are used as an alternative. Image availability is strongly affected by high cloud cover in growing season of the Midwest. Perennial native grasses flourish in April-May (Wang et al. 2011). Upon the USDA crop calendar (www.usda.gov/oce/weather/CropCalendars/), corn is planted in April-May and soybean in May-June depending on geographic regions. In 2007, only three low-cloud TM images were available in these three months: April 18, May 20, and June 21 (Table 1). The onemonth interval of this series highly restricts its capability of crop delineation. To enrich our data sets, the 8-day, 500-m MODIS reflectance images (MOD09A1) in 2007 are disaggregated to fill in the gaps. The final series are composed of 26 scenes (17 TM and 9 MODIS) with an average interval of $10 \pm 4.5$ days. The NDVI of each image is calculated from its red and near-infrared bands. The NDVI time series serve as the primary data source in this study.

Ground truthing samples come from past studies and published maps. The USDA CDL map in 2007 is classified from the 56-m imagery acquired by the Indian ResourceSat-1 Advanced Wide Field Sensor (AWIFS). It provides good training source for annual crops of corn, soybean and 
winter wheat. The 2007 CDL map also extracts double cropping of winter wheat-soybean (WWSoy). However, it does not delineate warm-season prairie grasses (WSG) from cool-season forage grasses (CSG) in pasturelands. In a previous project funded by Missouri Department of Conservation (MDC), we extracted warm-season grasses in MDC-managed tallgrass prairie remnants in the Cherokee Plain (Wang et al. 2010). Patches of these MDC prairie remnants within the study area are marked in Fig.1. These patches serve as training sources of WSG. The non-WSG grasses in the Cherokee Plain are treated as CSG sources and are extracted from the CDL map. It should be noted that national CDL products have undergone intensive training and validation at USDA NASS, and annual crops in major agricultural regions reached high accuracies of $80-90 \%$ (Boryan et al. 2011). However, in herbaceous grasslands where annual crops were not dominant, such as our study area, its classification errors may remain high. Caution should be taken when assuming CDL samples as "truth" data of this study.

For training data collection, a number of sample points for each crop are randomly extracted from the source maps (CDL or MDC prairie remnants). Points within small fields or close to field borders are removed. Surprisingly, the CDL-extracted wheat single cropping is extremely limited in the study area, and majority of winter wheat fields are classified as WW-Soy double cropping. Via visual interpretation of NDVI time series, we notice that the fall peak (high NDVI values during soybean growth) is not clear in a lot of these CDL-extracted WW-Soy fields. In practice, we only select those with apparently double growth cycles as our WW-Soy samples. The final numbers of training points for all crops are listed in Table 2. Only crops are examined. Other crops and non-crop lands (e.g. urban, water, forest) are masked out from the CDL map. 
Table 2 Ground truthing samples of annual crops and perennial grasses in the study area.

\begin{tabular}{|c|c|c|c|c|}
\hline \multirow{2}{*}{ Crop types } & \multicolumn{2}{|c|}{ Training } & \multicolumn{2}{|c|}{ Validation } \\
\hline & Points & Sources & $\begin{array}{l}\text { Crop fields } \\
\text { (CDL) }\end{array}$ & $\begin{array}{c}\text { Grass fields } \\
\text { (MDC }{ }^{*} \text { project) }\end{array}$ \\
\hline Corn & 83 & $\mathrm{CDL}$ & 455 & l \\
\hline Soybean & 52 & CDL & 429 & l \\
\hline Winter wheat & 56 & CDL & 50 & l \\
\hline $\begin{array}{l}\text { WW-Soy (double } \\
\text { cropping) }\end{array}$ & 40 & $\begin{array}{c}\text { CDL + NDVI } \\
\text { time series } \\
\text { visualization }\end{array}$ & 405 & l \\
\hline $\begin{array}{c}\text { Warm-season grass } \\
\text { (WSG) }\end{array}$ & 87 & $\mathrm{MDC}^{*}$ project & \multirow[t]{2}{*}{ / } & 256 \\
\hline $\begin{array}{c}\text { Cool-season grass } \\
\text { (CSG) } \\
*_{\text {Missouri Department o }}\end{array}$ & 96 & CDL & & 348 \\
\hline
\end{tabular}

All field-level CDL and MDC-grass polygons are used in validation process (Table 2). To simplify the process, a field is assumed a homogeneous class polygon. To reduce uncertainties, only field polygons larger than 50 acres (15×15 TM pixels) are extracted. Exceptionally, a 10acre threshold is used for WW because the CDL-extracted WW single cropping fields are surprisingly limited. Even so, more than 400 fields (>50 acres) are collected for corn, soybean and WW-Soy, respectively, but only $50 \mathrm{WW}$ fields (>10 acres) are available. Similarly, all MDC-classified WSG polygons larger than 50 acres are extracted. Given the predominant CSG pasturelands in the study area, we only extract MDC-classified CSG polygons with areas larger than 100 acres. A total of 1,943 validation fields are thus extracted. Other reference data, although not spatially explicit, include the county-level planting acreages of field crops in three counties (Barton, Vernon, and St. Clair) that are fully covered within the study area. These data are downloaded from the NASS Crop Quickstats database (http://quickstats.nass.usda.gov/). Our results of crop acreages in each county are statistically compared with these census records. 


\subsection{Methodological design}

This study applies the ESTARFM model to disaggregate the MODIS images in Table 1 and to generate the TM-like NDVI image series in the study area. The $1^{\text {st }}$-order derivatives of NDVI series are extracted and two critical timings are examined. Relying on unique timing sequence of each crop, a derivative-based decision tree is developed to classify annual crops and perennial grasses from the enhanced TM/MODIS NDVI time series. The objected-based segmentation is finally performed to remove in-field noises of the classification.

\section{Enhanced Spatial and temporal adaptive reflectance fusion (ESTARFM)}

Image fusion is performed to disaggregate the MODIS images in Table 1 to match the $30-\mathrm{m} \mathrm{TM}$ pixels. Orbits of the Landsat and Terra satellites are designed to pass the Earth surface at the same local time (10:30AM in mid-latitude region). For TM and MODIS images acquired on the same date, land reflectance and atmospheric conditions are assumed the same, biased by systematic sensor noises that are assumed stable spatially and temporally. Here we adopt the ESTARFM algorithm (Zhu et al. 2010) to create the enhanced TM/MODIS time series. To disaggregate a MODIS image acquired on certain date, the TM/MODIS pairs before and after this date are obtained, and two images in each pair are layer-stacked in the same band sequence in visible-near infrared region. For example, in Table 1 we have TM images on April $2^{\text {nd }}$ and $18^{\text {th }}$. To disaggregate the MODIS image on April $7^{\text {th }}$ (actually an 8-day composite on $7^{\text {th }}-14^{\text {th }}$ ), the MODIS images on $2^{\text {nd }}$ and $18^{\text {th }}$ are downloaded to obtain the TM/MODIS pair on each date. 
Take three dates $t_{0}, t$, and $t_{n}$, with $t$ representing the date for MODIS disaggregation, while $t_{0}$ (before $t$ ) and $t_{n}$ (after $\left.t\right)$ are the two dates with TM/MODIS pairs. At a pixel $(i, j)$, the predicted TM-like reflectance $\left(T M^{\prime}\right)$ at date $t$ can be written as:

$$
T M_{i, j, t}^{\prime}=T M_{i, j, t_{0}}+C_{i, j} \times\left(M O D_{i, j, t}-M O D_{i, j, t_{0}}\right)
$$

where $T M$ and $M O D$ are reflectance values of the pixel in the same TM/MODIS band, respectively. $C_{i, j}$ is the conversion factor at this pixel.

The conversion factor $C_{i, j}$ could be calculated from the two TM/MODIS pairs at $t_{0}$ and $t_{n}$. For pure MODIS pixels in relatively homogeneous land, it is assumed constant that is solely affected by atmospheric and systematic biases (Gao et al. 2006). In our study area, a 500-m MODIS pixel are often a mixture of multiple crop fields, and crop reflectance changes along its growth development. Therefore both spatial and temporal details should be taken into account. Here we treat the conversion factor $C_{i, j}$ as a function of reflectance changes in a linear mixing theory. When a MODIS pixel is split into $M$ numbers of TM-like pixels, each TM-like pixel serves as an endmember $(m)$ of the MODIS pixel. Given the short time elapse between $t_{0}$ and $t_{n}$, it is reasonable to assume that the rate of reflectance change is stable for all endmembers. Therefore, the conversion factor at pixel $(i, j)$ in Eq. 1 is actually a weighted linear regression of reflectance changes of all endmembers:

$$
C_{i, j}=\sum_{m=1}^{M} \frac{T M_{m, t_{n}}-T M_{m, t_{0}}}{M O D_{m, t_{n}}-M O D_{m, t_{0}}} \times W_{m}
$$

where $W$ is a weight matrix in a size of $M / 2$. The weight of each endmember is positively related its spectral similarity to the central pixel $(i, j)$. More details are described in Zhu et al. (2010). 
With Eq. 1 and 2, any MODIS image in Table 1 is disaggregated with TM/MODIS pairs before and after its acquisition date, and a TM-like image is created. With red and near-infrared bands of these data sets, the 26-layer NDVI time series are established.

Time series of NDVI derivatives: the "PG-0-PD" sequence

NDVI time series are always affected by atmospheric conditions and cloud residues. In previous experiences we found that, by smoothing the NDVI trajectories at a pixel, atmospheric effects could be reduced and crop development cycles are effectively revealed (Wang et al. 2010, 2011). Following the same procedure, a modified $2^{\text {nd }}$-order Savitzky-Golay filtering approach (Savitzky and Golay 1964) is used to smooth our NDVI time series. Fig.2 demonstrates the NDVI timeseries curves extracted from example pixels of six crops. Crop phenology can be revealed in these curves. For example, corn and soybean have similar development cycles although corn is known to be planted 1-2 weeks earlier (USDA Crop Calendar). Winter wheat reaches peak NDVI in early spring and rapidly dries down before harvesting. The WW-Soy has apparent twocycle seasonality. Grasses have longer growing length although WSG starts growing later and becomes senescent earlier than CSG.

With a relatively small size of NDVI time series (26 scenes), high uncertainties remain for regular phenology-based crop mapping. In this study, we establish a derivative-assisted change analysis of NDVI time series to reduce these uncertainties by checking into the timing of reflectance change along crop growth. With a 3-point Lagrangian interpolation, the $1^{\text {st }}$ derivative at point $i$ along the NDVI time series is calculated as:

$$
L_{i}(N D V I)^{\prime}=\frac{\sum_{k=0}^{n} \prod_{l=0, l \neq k}^{n}\left(N D V I-N D V I_{l}\right)}{\prod_{k=0, k \neq i}^{n}\left(N D V I_{i}-N D V I_{k}\right)}
$$


where $n$ is the length of the Lagrangian interpolation ( $n=3$ in this study).

The $1^{\text {st }}$ derivative in Eq. 3 represents temporal change of NDVI on a specific date (with a unit of day-of-year, or DOY). For each crop, a pixel is randomly selected from the enhanced TM/MODIS time series. Its trajectories of NDVI and the $1^{\text {st }}$ derivatives are displayed in Fig.2. The NDVI trajectory reveals crop's phenological development within its growing season, e.g. start of season and end of season. The date of the maximal derivative represents the time of peak growing (PG), while that of the minimal derivative is the time of peak drying (PD) along crop development. The date with $1^{\text {st }}$ derivative $=0$ occurs when a crop reaches its maximal NDVI, or peak growth stage. To visually compare the two curves in the same range, NDVI is multiplied by 100 and its derivative is multiplied by 10 (Fig.2).

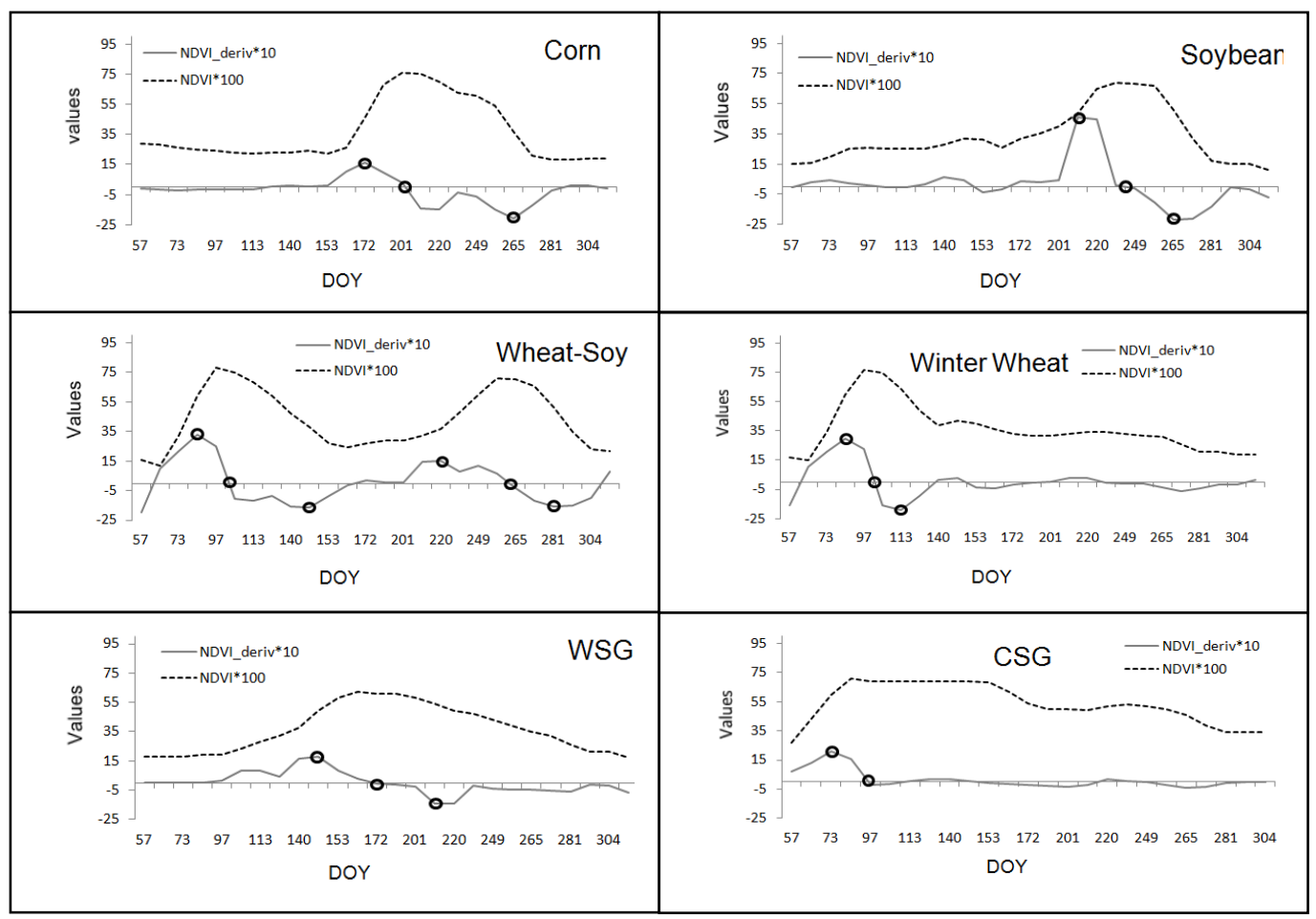

Figure 2 Example trajectories of NDVI $(\times 100)$ and $1^{\text {st }}$-order derivatives $(\times 10)$ of six crops.

The three symbols marked on each derivative curve define the "PG-O-PD" sequence. 
This study introduces a "PG-0-PD" sequence of the derivative series to define crop's complete growing cycle. As marked in Fig.2, all single crops have one growing season, i.e. one "PG-0-PD" sequence along the derivative time series. The Wheat-Soy apparently has two sequences that explain its double-cropping feature. The CSG has extremely long growing season and remains green until early winter. In the example curve in Fig.2, its derivative series does not show a clear PD. It is also clear in the figure that the timings of PG and PD vary with crops, indicating the potential of crop delineation based on these two critical timings. Local variations of NDVI along the smoothed trajectories contribute to the inflection points, or local peaks and troughs, in the derivative series. In Fig.2, these local curvatures result in the fluctuation of the derivative trajectories, but do not change the "PG-0-PD" sequence. Representing the global maximum and minimum of derivatives in a growing season, the PG and PD have their absolute values much higher than those at the inflection points and therefore, could be easily identified in the derivative series.

\section{Derivative-based decision tree}

The PG dates reveal the time of crop peak growing (not peak greenness). With crop samples listed in Table 2, the PG dates for each crop are extracted. Crop samples with their PG dates falling on each image acquisition date are counted and their probability distributions against DOY are plotted in Fig.3. The PG spans of all crops are narrow, mostly clustered in 2-3 dates with one predominant date. The limited overlay of PG dates among crop types indicates its capability of crop classification. 


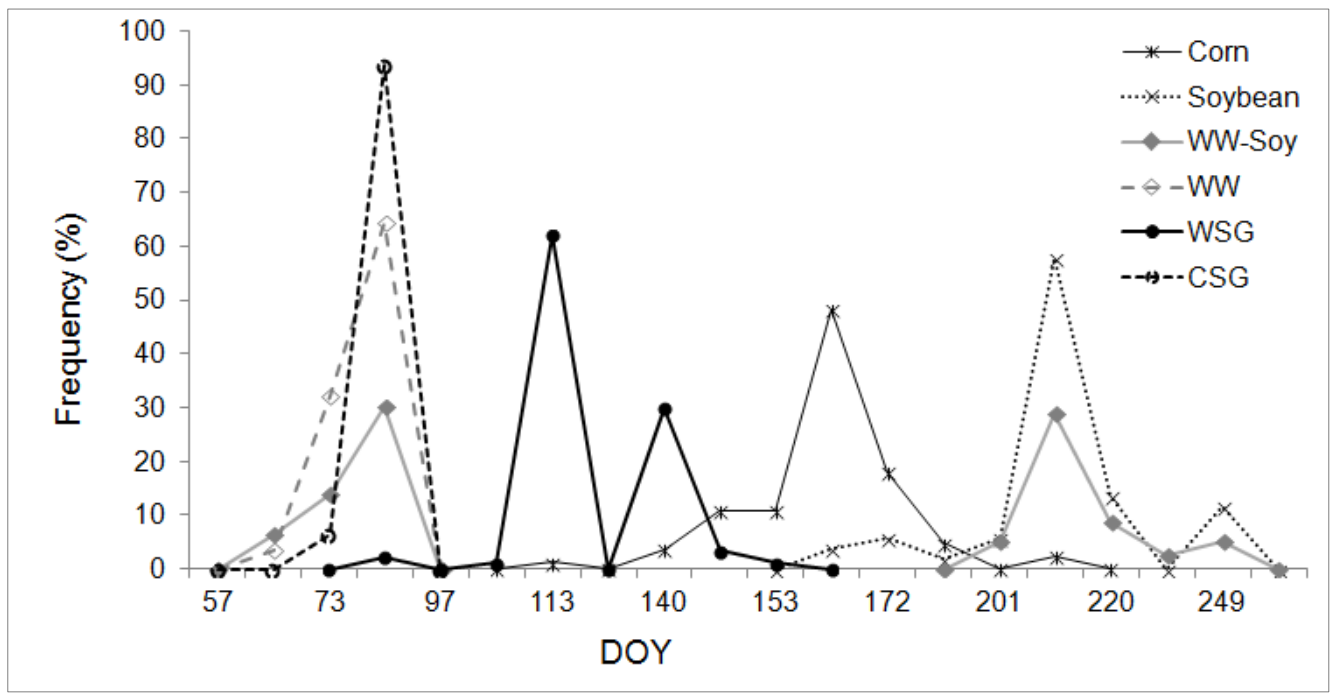

Figure $3 \quad$ Probability distributions of the PG dates for the six crops.

The PG dates of three crops (WW, WW-Soy and CSG) fall in the same range in early spring. WW and WW-Soy could be identified by an apparent trough (PD) when wheat rapidly dries up. WW-Soy has unique double PG dates; one in early spring and the other in fall. Due to the mixed, heterogeneous growth of native prairie grass species in less-managed grasslands, WSG shows two modes; a primary one on DOY 113 (image \#7) and a smaller one on DOY 140 (image \#9), revealing its rapid greening in April-May. Agreeing with the crop calendar in the study area, the PG dates of corn are commonly earlier than those of soybean. The primary PG date of corn is DOY 161-169 (image \#12-13) while that of soybean is DOY 217 (image \#16). A small number of soybean samples have similar PG dates as corn on DOY 161-172 (images \#12-13), possibly from the mixed corn-soybean fields in these samples. A small cluster of soybean PG dates occurs on DOY 249 (image \#19), but is less a concern because soybean has the latest PG dates among all crops. 
Fig.4 demonstrates a graphic decision tree for crop delineation relying on unique distributions of PG and PD dates of crops. Crop growth is split into two seasons. The PG dates of all crops except soybean fall in March-June. In this season WSG is delineated from CSG by a later PG range in April-May. Corn has the latest PG dates ranging from late May to early July. WW (and the $1^{\text {st }}$ cycle of WW-Soy) is identified with an apparent PD trough while other crops do not have such feature in this season. The PD range of WW is found widespread that may be related to post-harvest managements (e.g., idle, tilt/non-tilt and soybean planting) in the study area. In the $2^{\text {nd }}$ season, the PG dates of soybean (and the $2^{\text {nd }}$ cycle of WW-Soy) fall in July-August. WW-Soy is finally extracted by its unique two-season feature in the derivative series. Note that this approach does not require the absolute NDVI values in the classification.

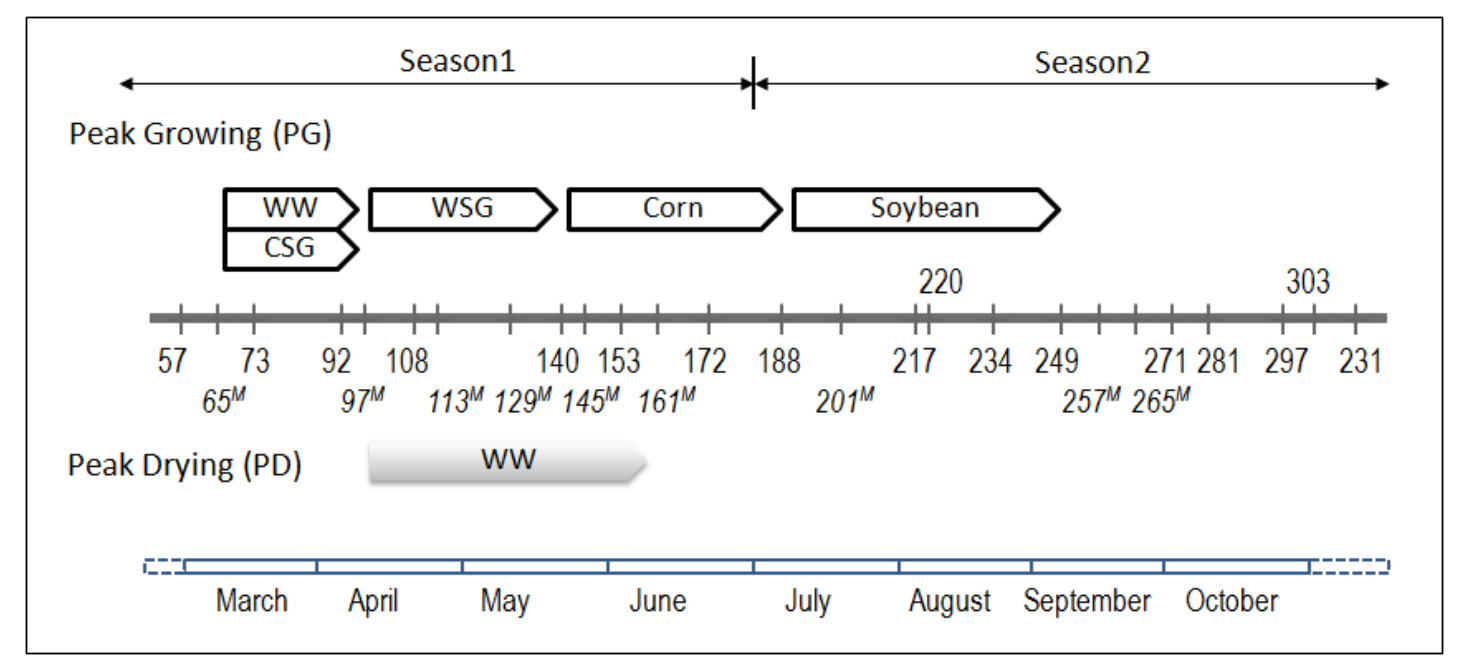

Figure 4 Graphic demonstration of the PG/PD-based decision tree. Note the intervals of image acquisition are uneven. A date marked with " $M$ " indicates a MODIS image.

The two derivative thresholds (PG and PD) in the decision tree are determined from their probability distributions of crop samples. The PG values in Fig.5a are the maximal derivatives 
that occur at crop's peak growing time. Except for a few samples of WW and WW-Soy, all of six crops had PG > 5. Only 6\% of WW and 7.5\% of WW-Soy samples do not meet this threshold. Therefore, we set up the threshold of PG > 5 to delineate crops from non-crop pixels. All pixels not satisfying are defined as "non-crop" and are not considered in our analysis. The PD values in Fig. $5 \mathrm{~b}$ are the minimal derivatives that occur at crop's peak drying time. It is used to identify WW and WW-Soy because they rapidly dry up for harvesting. Their probability distributions showed that $87.5 \%$ of WW and $92.3 \%$ of WW-Soy samples have PD $<-7$, while only $2.1 \%$ of CSG meet this threshold. Therefore, we set up the threshold of PD $<-7$ in the $1^{\text {st }}$ Season (as marked in Fig.4) to delineate WW and WW-Soy from grasses, specifically. Corn and soybean have wide ranges of PD values. However, their PD dates do not occur in the $1^{\text {st }}$ season and thus do not affect the delineation in this step.

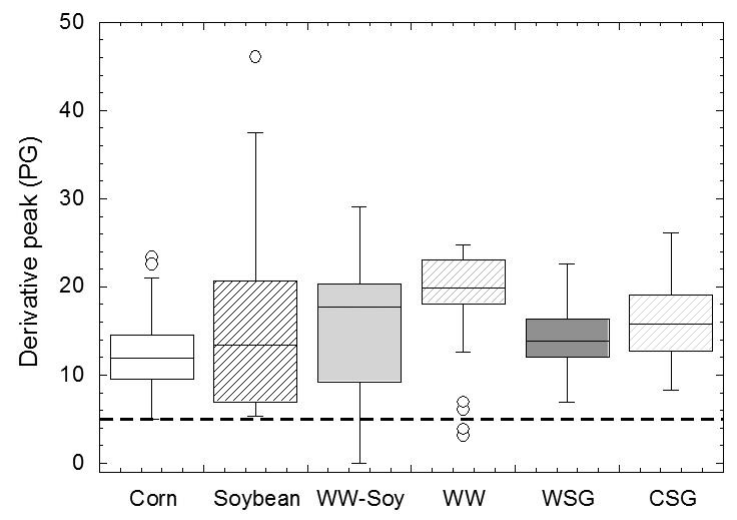

(a)

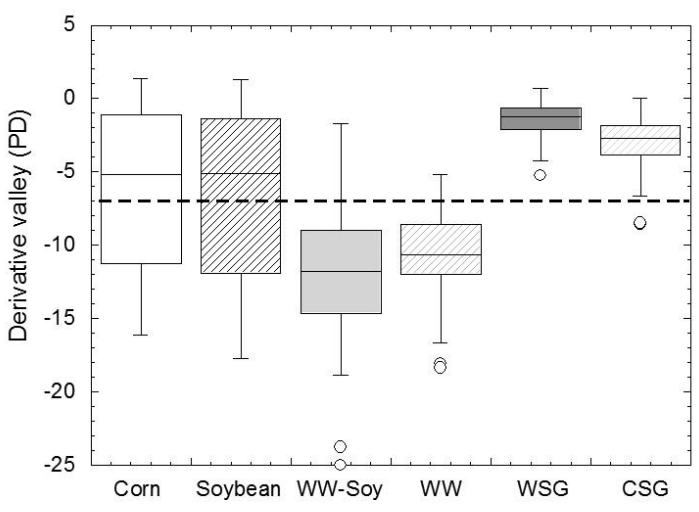

(b)

Figure $5 \quad$ Boxplots of $P G(a)$ and $P D(b)$ for the 6 crops. The $P G>5$ and $P D<-7$ threshold lines are marked in each plot.

\section{$\underline{\text { Class segmentation }}$}

The decision tree classification above solely relies on the PG and PD derivatives and their dates at each pixel. Classification noises in a field or along field borders are inevitable due to in-field 
spectral variation or mixed pixels. To overcome these problems, here we perform a postclassification segmentation using the Object-Based Image Analysis (OBIA) technique (Blaschke 2010). Segmentation is a bottom-up region-merging process in which pixels of an image are grouped into homogeneous regions based on pre-defined parameters including scale, color, shape, smoothness and compactness (Haralick and Shapiro 1985; Peña-Barragán et al. 2011). The basic idea of OBIA is to construct a hierarchical network of homogenous objects that, for crop classification in this study, match the boundaries of crop fields as revealed in CDL maps.

The object segments are extracted from the 26-layer NDVI time series using a multi-resolution segmentation algorithm in the Definiens eCognition Developer 8. In our previous study (Li et al. 2015), crop segmentation in the study area was found optimal at a scale factor of 15 with a color/shape weight of $0.7 / 0.3$ and a compactness/smoothness weight of $0.5 / 0.5$. After pure objects across the study area are extracted, a majority filter is performed to our classification results and the dominant class is assigned to each object. Homogeneous fields of the 6 crops are thus extracted.

\section{Results}

\section{Crop classification}

The segmented classification results are visually compared with the CDL map in Fig.6. The general land use patterns in the two figures matched well. Herbaceous grasslands and pastures were dominant, scattered with annual crops in the study area. Our classification results in Fig.6a differentiate the warm-season prairie grasses (red patches) from cool-season forage grasses, while the CDL map in Fig.6b groups all grass pixels into one category - grassland/pasture. 
Except WSG, the classified results in Fig.6a follow the same color scheme as CDL. Areal statistical comparisons were conducted in next section. The CDL map also extracted other crops such as sorghum $(0.11 \%)$, alfalfa $(0.01 \%)$ and fallow/idle cropland $(0.01 \%)$ in the study area. At such small acreages, these crops were not examined in this study.

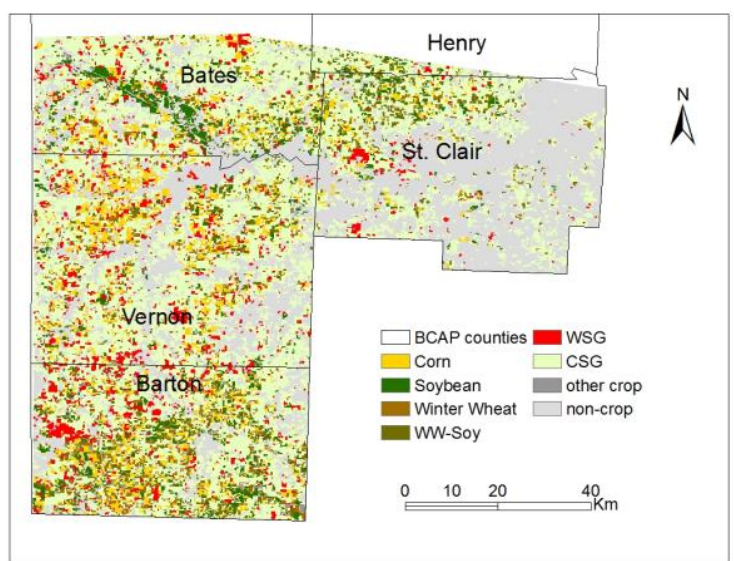

(a)

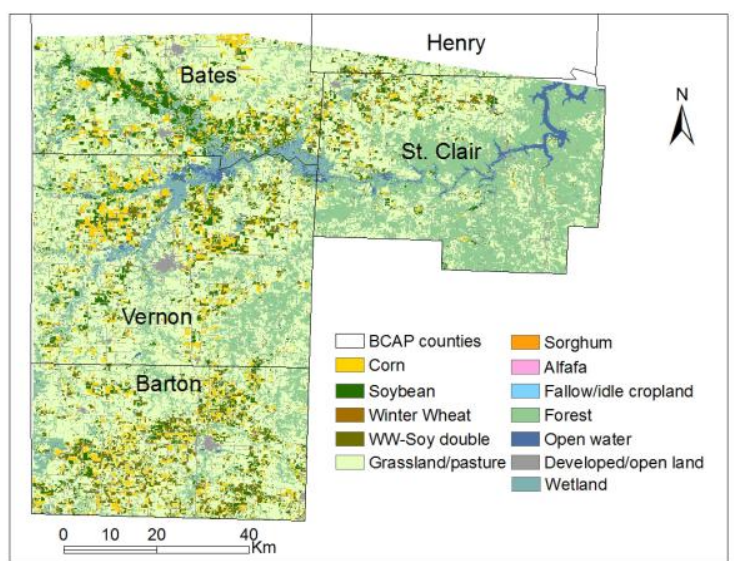

(b)

Figure 6 Crops classified in this study (a) and the CDL map (b). Other classes are also displayed in (b) to demonstrate the land use/land cover patterns of the study area.

Warm-season prairie grasses are of the primary interest in the BCAP Project Area 1. Fig.7 displays the extracted WSG patches of the study area. Also marked are the 18 prairie remnants managed by MDC as conservation areas (Wang et al. 2011). Most of these remnants, ranging from 40 to 1,700 acres in size, are primarily prairie grasses in mixture with forests, annual crops and pastures under MDC's practical land management. Detailed description is available in the MO Conservation Atlas Area Summary (http://mdc4.mdc.mo.gov/applications/moatlas). As shown in Fig.7, percent covers of classified WSG in these prairie remnants vary from $44 \%$ of the Wah-Kon-Tah Prairie to 99\% of the Gay Feather prairie. The largest remnant in Fig.7 is the Bushwacker Lake Conservation Area. Historically tallgrass prairie covered all of the 4,500 acres 
in this land. Although much of the original prairie has been converted to annual crops or pastures seeded with cool-season forage grasses, more than 1,400 acres are being restored as prairie remnants (MDC 2015). These WSG patches occupy 57\% of the conservation area in the classification results. Other large prairie remnants, for example Osage Prairie (89\%), Prairie State Park (88\%), and Taberville Prairie (86\%), are also clearly identified in our class map. Across the study area, small WSG patches in private pasturelands were also identified, revealing the biomass potential in this pasture-dominated BCAP land.

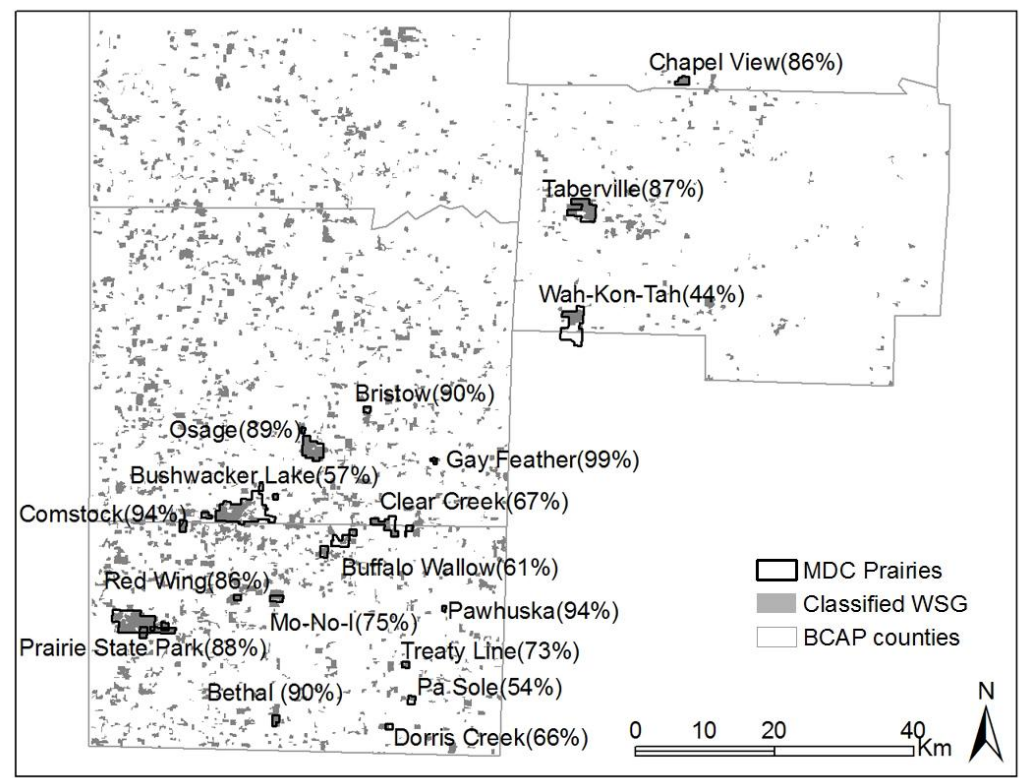

Figure 7 The classified WSG patches and the 18 MDC-managed prairie remnants.

\section{$\underline{\text { Comparison with CDL and MDC project results }}$}

An error matrix was calculated for validation analysis (Table 3). Given the fact that the CDL map is the only published source for annual crops and the MDC project as the only source for WSG, we compared our classification against these two source maps in a large number of validation fields (listed in Table 2). Also, since the WW single cropping fields were extremely 
limited in the CDL map, we combined WW and WW-Soy in calculating the producer's, user's and overall accuracies. Further comparison about WW and WW-Soy was described later.

Table 3 Error matrix of our classification (pixel-based and segmented) against the CDL- and MDC-extracted crop fields.

\begin{tabular}{|c|c|c|c|c|c|c|c|c|c|}
\hline & \multicolumn{6}{|c|}{ CDL fields } & \multicolumn{2}{|c|}{ MDC grass fields } & \\
\hline \multirow{10}{*}{ 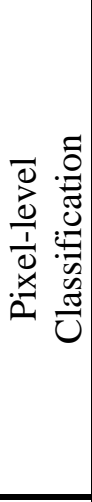 } & & & Corn & Soybean & WW & WW-Soy & WSG & CSG & User's \\
\hline & \multicolumn{2}{|l|}{ Corn } & 310 & 53 & 0 & 0 & 5 & 2 & $83.78 \%$ \\
\hline & \multicolumn{2}{|c|}{ Soybean } & 81 & 213 & 5 & 7 & 9 & 0 & $67.62 \%$ \\
\hline & \multirow{2}{*}{\multicolumn{2}{|c|}{$\begin{array}{l}\text { WW } \\
\text { WW-Soy }\end{array}$}} & 0 & 1 & 7. & 131 & 0 & 2 & \multirow{2}{*}{$96.85 \%$} \\
\hline & & & 1 & 3 & 28 & 172 & 0 & 4 & \\
\hline & \multirow{2}{*}{ Grass } & WSG & 39 & 83 & 1 & 0 & 219 & 1 & $63.85 \%$ \\
\hline & & CSG & 24 & 76 & 9 & 95 & 23 & 339 & $59.89 \%$ \\
\hline & \multirow{2}{*}{\multicolumn{2}{|c|}{\begin{tabular}{|l} 
Total \\
Producer's
\end{tabular}}} & 455 & 429 & 50 & 405 & 256 & 348 & \\
\hline & & & $68.13 \%$ & $49.65 \%$ & & $4.29 \%$ & $85.55 \%$ & $97.41 \%$ & \\
\hline & \multicolumn{9}{|c|}{ Overall accuracy: $\quad \mathbf{7 3 . 0 3 \%}$} \\
\hline \multirow{10}{*}{ 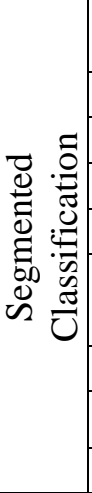 } & & & Corn & Soybean & WW & WW-Soy & WSG & CSG & User's \\
\hline & Corn & & 344 & 39 & 0 & 1 & 7 & 3 & $86.43 \%$ \\
\hline & Soybe & & 72 & 227 & 3 & 8 & 12 & 0 & $71.84 \%$ \\
\hline & WW & & 0 & 0 & 4 & 139 & 0 & 2 & \multirow{2}{*}{$98.06 \%$} \\
\hline & WW-S & & 0 & 1 & 31 & 181 & 0 & 1 & \\
\hline & \multirow{2}{*}{ Grass } & WSG & 28 & 87 & 1 & 0 & 206 & 1 & $60.34 \%$ \\
\hline & & CSG & 11 & 75 & 11 & 75 & 31 & 341 & $59.16 \%$ \\
\hline & \multirow{2}{*}{\multicolumn{2}{|c|}{$\begin{array}{l}\text { Total } \\
\text { Producer's }\end{array}$}} & 455 & 429 & 50 & 405 & 256 & 348 & \\
\hline & & & $75.60 \%$ & $52.91 \%$ & & $8.02 \%$ & $80.47 \%$ & $97.99 \%$ & \\
\hline & \multicolumn{9}{|c|}{ Overall accuracy: $\quad 75.81 \%$} \\
\hline
\end{tabular}

In comparison with the 1,943 large validation fields, the overall agreement of our classification reached $73.03 \%$ in pixel level and $75.81 \%$ after segmentation. The OBIA segmentation slightly increased the accuracies of annual crops by reducing their in-field noises. Oppositely, the pixellevel accuracies of WSG were higher than segmentation although those of CSG remained similar. This may attribute to the naturally heterogeneous growth of WSG species in less-managed grasslands. Among all annual crops, soybean had the lowest agreement with its producer's 
accuracy of $49.65-52.91 \%$ and user's accuracy of $67.62 \%-71.84 \%$ in two levels. The MDC-

extracted WSG and CSG fields were best recognized in our pixel-level classification (highest producer's accuracies). However, a large number of soybean and WW-Soy fields in CDL maps were misclassified as grasses, which resulted in low user's accuracies for WSG and CSG. More discussion about soybean classification was described in next section. Given that the 2007 CDL map is classified from 56-m satellite images and bears its own uncertainties, the derivative-based classification in this study effectively identified the major crops in the study area.

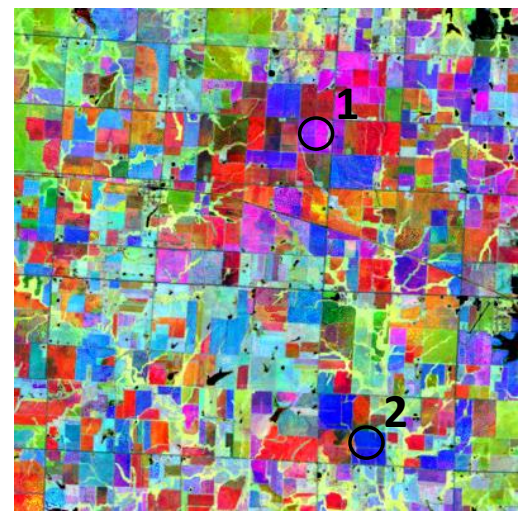

(a)

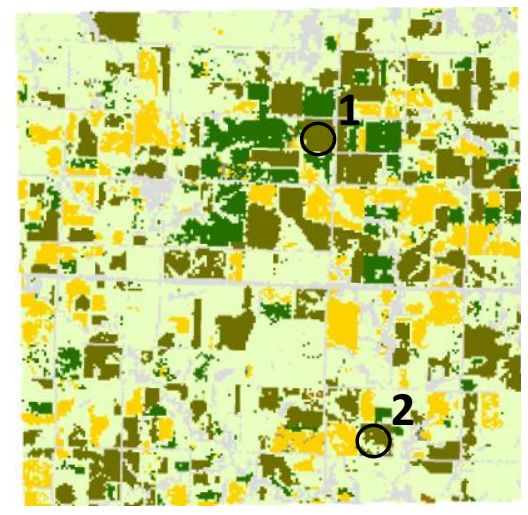

(c)

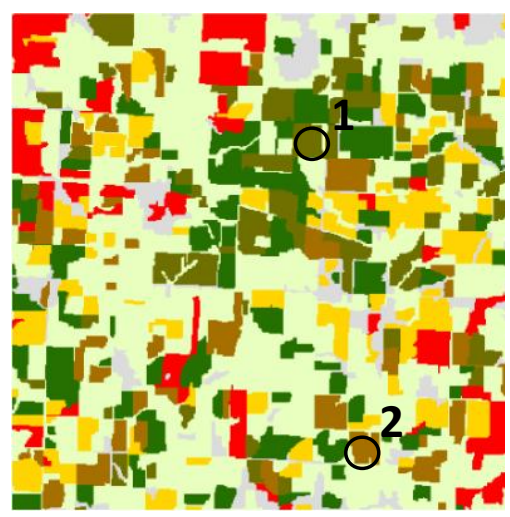

(b)

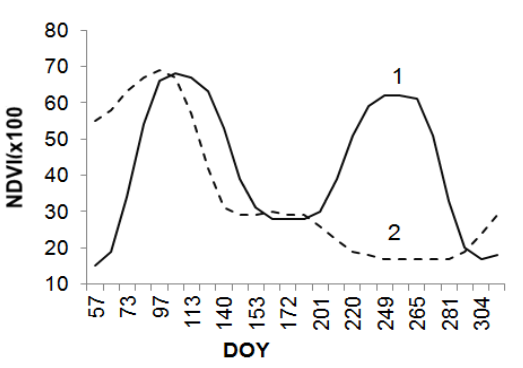

(d)

Figure 8 Demonstration of WW and WW-Soy classification in a subset: (a) NDVI composite (DOY 257/161/97 as R/G/B); (b) our classification; (c) CDL map; and (d) NDVI timeseries trajectories of two example fields. The map legends of $(b)$ and $(c)$ are the same as Fig.6. 
The WW and WW-Soy confusion in the CDL map was visually examined from NDVI time series. Phenological features of winter wheat such as early growth and rapid drying up in spring were clear in the trajectories. To visually demonstrate the differences between CDL and our classification, a subset of the study area in Barton County was selected to compare both results in Fig.8. Fig.8a is the visual display of NDVI time series using DOY257 (9/14), 161 (6/10) and 97 (4/7) as R, G, and B, respectively. As listed in Table1, all three images are MODISdisaggregated. Even so, field boundaries are quite clear in Fig.8a, indicating the feasibility of TM/MODIS image fusion in crop mapping. Both WW and WW-Soy double cropping were common in our classified results (Fig.8b). In the CDL map (Fig.8c), however, almost all wheat fields were classified as WW-Soy double cropping. Note that the CDL map in 2007 had a 56-m resolution and therefore, crop boundaries were not as clear. Except the major crops, other CDL classes in Fig.8c are merged to "other crop" and "non-crop" to visually match with Fig.8b. Two example crop fields (1 and 2) were randomly selected in the subset image. From their time-series trajectories (Fig.8d), we can easily interpret that Field 1 was WW-Soy double cropping (2-cycle) while Field 2 was a typical single-cropping wheat field (1-cycle). One cycle was actually represented by a complete PG-0-GD sequence as shown in Fig. 2. These differences of WW and WW-Soy fields were recognized in our classification but not in the CDL product.

In the error matrix in Table 3, a total of $35 \mathrm{WW}$ and $320 \mathrm{WW}-$ Soy validation fields were still classified as WW or WW-Soy. These fields were also visually examined according to these trajectory features. Here we define the fields with apparent spring peak as " 1 -cycle", and those with apparent two peaks, one in Spring and the other in Fall, as "2-cycle". There were also some 
fields with apparent spring peak but a lower, less apparent fall peak, possibly affected by mixed fields or grass covers in non-tilted fields that remain green in fall. These fields are defined as "weak 2-cycle" that may hold higher confusion in classification. Table 4 reveals the high confusion of WW and WW-Soy fields in the CDL map. Among the 35 CDL-extracted WW fields, 23 of them actually had 2-cycle patterns and only 5 were 1 -cycle. These fields were more actually recognized in our classification into $31 \mathrm{WW}$-Soy and 4 WW fields. Similarly, almost half of the 320 CDL-extracted WW-Soy fields were classified as WW because of their 1-cycle patterns. Those with 2-cycle patterns were more likely classified as WW-Soy instead. Via visual interpretation, it is reasonable to claim that our classification better delineated WW and WW-Soy fields than the CDL map.

Table 4 Visual comparison of WW and WW-Soy fields between CDL and our classification.

\begin{tabular}{c|l|c|c|c|c}
\multirow{2}{*}{ CDL } & \multicolumn{3}{|c|}{ Our classification } & \multicolumn{3}{c}{ Visual interpretation } \\
\cline { 4 - 6 } & & & 1-cycle & Weak 2-cycle & 2-cycle \\
\hline $\begin{array}{c}\text { CDL_WW } \\
(35)\end{array}$ & WW & 4 & 2 & 1 & 1 \\
\cline { 2 - 6 } & WW-Soy & 31 & 3 & 6 & 22 \\
\hline $\begin{array}{c}\text { CDL_WW-Soy } \\
(320)\end{array}$ & WW & 139 & 109 & 13 & 17 \\
\cline { 2 - 6 } & WW-Soy & 181 & 4 & 40 & 237 \\
\hline
\end{tabular}

For total crop acreages of the study area (Fig.9), the pixel-counted and object-counted planting areas in our classification were similar, indicating that the OBIA segmentation in this study fairly extracted homogeneous crop fields. Corn acreage of our classification was similar to CDL but soybean was much higher. Upon the USDA crop census, both WW and WW-Soy double cropping practices were common in the Midwest. In Fig.9, however, the CDL-extracted WW acreage is unreasonably low, only $21 \mathrm{~km}^{2}$ over the study area. This also supports that CDL failed to effectively identify WW and WW-Soy fields than CDL. Native WSG prairies were not 
available in the CDL products. When CSG and WSG were combined, total grassland areas were approximately $3,232 \mathrm{~km}^{2}$ for pixel-based and $3,358 \mathrm{~km}^{2}$ for object-based results, which was comparable to the CDL grasslands/pastures $\left(3,337 \mathrm{~km}^{2}\right)$.

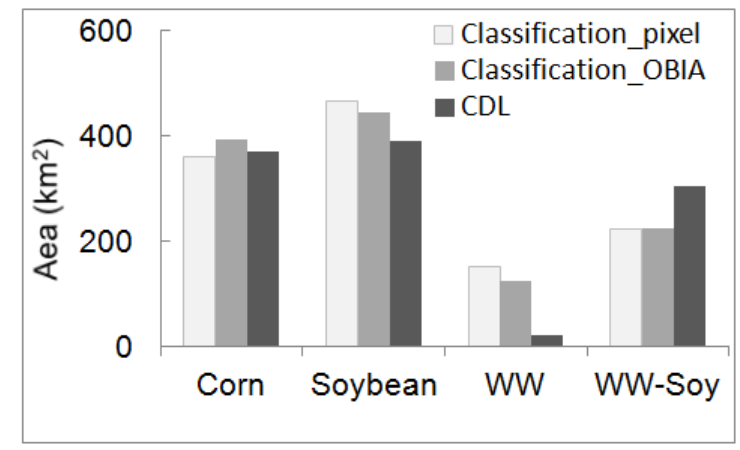

Figure 9 Crop planting areas among pixel-based classification, objected-based classification, and CDL map of the study area.

\section{Comparison with County-level Crop Census}

To further examine the discrepancy between CDL and our classification, we downloaded the county-level planting acreages of field crops in three counties (Barton, Vernon, St. Clair) of the study area. Double cropping acreages in 2007 were not recorded in Missouri counties. For soybean, both single and double cropping records were available in a broader, Agricultural District level (multi-county). Upon these records, soybean and WW-Soy acreages were similar in the Southwest AD (where Barton is located), agreeing with our classification in the subset (Fig.8). For winter wheat, survey records in Missouri did not differentiate WW single and WWSoy double cropping. Here we combined soybean and WW-Soy as total soybean acreage (Soybean), and winter wheat and WW-Soy as total wheat (Wheat). Crop areas of the three counties were compared between our classification and CDL against the county-level survey records (Fig.10). 
Two acreage records of field crops were available in USDA survey records: planted area and harvest area. The harvest acreage of each crop was often slightly lower than the planted acreage. In Fig.10, the straight (harvested) and dashed (planted) lines are close to each other, outlining the baseline that the comparison is against with. It should be noted that, although providing valuable statistical information, the county-level crop census data were not real measurements and thus could not be treated as ground "truth" of the comparison.

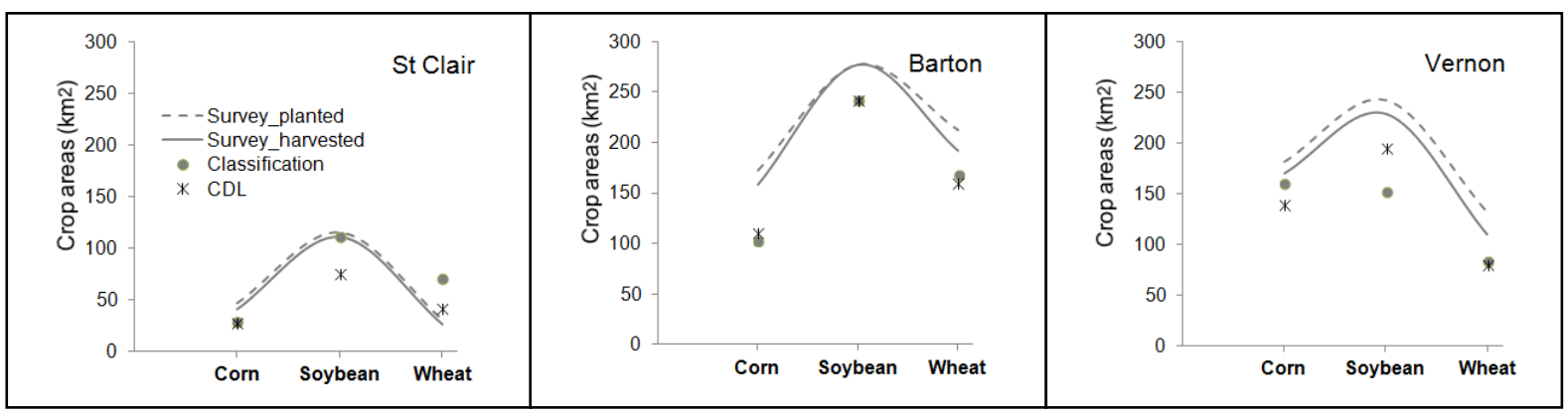

Figure10 Comparison of total acreage between the classified and CDL map in each county.

The planted and harvested survey records mark the baseline of the comparison.

For the three counties, soybean had higher acreage than other crops (Fig.10). Although total crop areas were lower than the surveyed records, the proportions of corn, soybean and wheat in both CDL and our classification followed the survey baselines in all three counties. St. Clair County is heavily forested and has the least crop areas (as shown in Fig.6b). Crop acreages of our classification agreed well with CDL in all counties especially Barton. Exceptionally, soybean acreage of our classification was about $43 \mathrm{~km}^{2}$ lower than CDL in Vernon but $36 \mathrm{~km}^{2}$ higher in St Clair. These per-county discrepancies indicated the need of methodological modification for soybean delineation in this study. 
Harvested acreages of hay and haylage in Missouri were also available in the 2007 census data. However, it was found that their records were unreasonably low in the study area, only 200-300 $\mathrm{km}^{2}$ in county level while the grassland/pasture areas in the CDL product reached $500-1,000 \mathrm{~km}^{2}$. For this reason we did not compare grass acreages with census records. Combining WSG and CSG in our classification results, the areas were similar as the CDL results (Table 5). Non-crops (urban, water, forest, etc.) in the CDL product were not considered in our classification. Therefore, uncertainties of grasses in this study primarily came from misclassification with annual crops. Assuming the CDL product as "truth" data, the relative root-mean-square error of grass classification in the three counties was $5.82 \%$. The error was reasonably low in this pasture-dominated study area.

Table 5 Areal comparison of grasslands between CDL and our classification in three counties.

\begin{tabular}{l|l|l}
\hline & \multicolumn{2}{|c}{ Grass area $\left(\mathrm{km}^{2}\right)$} \\
\cline { 2 - 3 } & CDL & $\begin{array}{l}\text { Classification } \\
\text { (WSG+CSG) }\end{array}$ \\
\hline St Clair & 646.27 & 598.53 \\
\hline Barton & 848.06 & 869.87 \\
\hline Vernon & 1123.76 & 1194.37 \\
\hline RMSE: & $50.80 \mathrm{~km}^{2}$ \\
Relative RMSE: & $5.82 \%$ & \\
\hline
\end{tabular}

\section{Discussion}

This study takes advantage of critical timings of crop development for its delineation in agricultural lands. Represented by the maximal $1^{\text {st }}$-order derivative in NDVI time series, the peak growing time reflects the moment of crop's rapidest physiographical development, while the commonly applied peak growth date (with maximal NDVI) reveals the saturation of growth when a crop reaches its peak greenness. After reaching peak growth, crop stays vigorously green before it dries up for harvesting. For this reason, peak growth dates of annual crops in the same 
season are often mixed in time-series analysis. Our study finds that each crop holds a clear "PG0-PD" sequence, with which crops can be better identified relying on their unique timings of development. Past studies have reported that extraction of phenological matrices such as start of season is highly affected by cloud noises in NDVI time series and smoothing techniques (Wang et al. 2011; 2015). Due to the limited layers (26 scenes) in a yearly period, the TM-like NDVI time series in this study cannot be as smooth as those from the 8-day, 46-layer MODIS data in our past studies (e.g., those demonstrated in Wang et al. 2011). Theoretical simulations such as the Asymmetric Gaussian model (Lu et al. 2013) are also problematic. Therefore, the enhanced TM/MODIS time series could not simply adopt the regular phenology-assisted classification approaches.

This study finds that a crop only has one "PG-0-PD" sequence in its $1^{\text {st }}$-order derivative time series. Although the curvature of derivatives is affected by local NDVI variations, the PG and PD represent global maximum and minimum of the derivative series and are not confused with inflection points (local peaks). With only two timing variables for six major crops, our approach provides an easy and robust way of crop mapping. Taking advantage of TM/MODIS reflectance fusion, the enhanced satellite time series reached an average of 10-day interval in a yearly period. The derivatives in this study are calculated against DOY and therefore, the uneven interval of image acquisition does not significantly affect the classification results. Moreover, at 30-m spatial resolution, the TM/MODIS fused image series reveal clear boundaries of crop fields, with which the object-based analysis reduces in-field classification noises and extracts clean, fieldlevel crop polygons. Regionalization of NDVI time series identifies in-field homogeneous objects that are later assigned into the dominant class. In this way, it better reveals individual 
crop fields than the pixilated CDL maps. While accuracies of regionalization rely on the selection of spatial scale in the OBIA process, a scale of 15 pixels used in this study matches an average object size of $450 \mathrm{~m}$ in length, fairly agreeing with the common knowledge of the 20-ha average field size in the Midwest (Hunt et al. 2010).

With only two timing variables (PG and PD) involved, our classification results are not always satisfying, especially for soybean as a late-planting summer crop. The corn-soybean rotation is common cropping practice in the Midwest. A soybean field is often planted with corn in previous year and is left idle after corn harvesting especially in no-tilt fields. Next year soybean is planted after pesticide and tillage operations in late April - early May (Baffaut et al. 2001). Soybean has the lowest accuracy in error matrix (as shown in Table 3) that could be interpreted in several aspects. First, high confusion between corn and soybean occurs. It is reasonable because of their similar crop calendars and development cycles. Second, soybean has a late planting date, and its misclassification to CSG and WSG grasses may come from green covers in non-tilt fields before soybean planting, which results in longer NDVI trajectory. Third, soybean could also be confused with CSG grasses in the $2^{\text {nd }}$ season. The CSG grasses often turned senescent in hot summers of the Midwest (Wang et al. 2011). With temperature cooling down in fall, CSG grasses resumed a $2^{\text {nd }}$ growth when soybean started peak growing.

Interestingly, the discrepancy of soybean acreage between our classification and CDL varies with counties. As shown in Fig.10, our classification matches all crops well with CDL in Barton, underestimates soybean in Vernon and overestimates it in St Clair. It may deserve further examination to check into of strategies of soybean cropping activities (e.g., planting calendar, 
fertilization and irrigation) in different geographic areas. For example, except the primary cornsoybean rotation, Baffaut et al. (2001) described several other rotation strategies such as soybean-wheat, corn-soybean-soybean, and corn-soybean-wheat/soybean double cropping in southwestern Missouri. Inclusion of soybean samples under different management activities may reduce its confusion from grasses in our approach.

The MODIS products at different spatial and temporal resolutions hold different disaggregation capabilities for TM/MODIS fusion, and therefore, affect the effectiveness of our proposed approach. This experimental study tested the MOD09A1 data because its 8-day composite maximally reduces cloud covers that are frequently observed in growing season. Spectral variation in an 8-day period, however, could be significant in critical growing stages. In days with good atmospheric conditions, daily surface reflectance products such as MOD09GA may better match the paired TM image during the TM/MODIS fusion. Those at 250-m resolution (daily MOD09GQ or 8-day MOD09Q1) may also reduce uncertainties from mixed crop fields. Comparison of these MODIS products in TM/MODIS fusion deserves further investigation.

Finally, native prairie grass is one of the primary energy crops recognized in the United States. While it has been planted under various conservation programs in past decades, spatial distributions of warm-season native prairie grasses have not been mapped in any national land cover databases. Especially important for the BCAP project, this experimental study provides the first map layer of perennial prairie grasses in this BCAP land. Even for annual crops, results of this study may provide supplementary information for national CDL products. The winter wheat single cropping and wheat-soybean double cropping fields, for example, are better delineated 
based on their one- and two-season cycles in NDVI time series. Overall, our classification results could serve as a base map to monitor agricultural land use change and biomass crop establishment in the BCAP lands, and eventually to assist bioenergy policy making at regional scale.

\section{Conclusion}

This study performed crop classification based on the unique timings of crop development in the BCAP land in southwestern Missouri. With an enhanced, 10-day TM/MODIS NDVI time series in 2007, a unique "peak growing (PG) - 0 - peak drying (PD)" sequence for each crop was identified in its $1^{\text {st }}$-order derivative series, and a decision tree was developed to delineate corn, soybean, winter wheat, wheat-soybean double cropping and two perennial grasses (warm-season vs. cool-season). The overall accuracy reached $76 \%$ against the CDL product. Winter wheat single cropping and wheat-soybean double cropping fields were much better delineated than the CDL product. Soybean, as a late-planted summer crop, had the lowest agreement with CDL, which may be improved by considering more details about cropping management activities. The primary goal of the BCAP Project Area 1 is to re-establish perennial prairie grasses (switchgrass) in croplands. Our classification of warm-season prairie grasses reached good agreement with prairie remnants managed by Missouri Department of Conservation, and could assist bioenergy land use conversion in this BCAP land.

\section{Acknowledgements}

This research is supported by Agriculture and Food Research Initiative Competitive Grant no. 2012-67009-22137 from the USDA National Institute of Food and Agriculture. We thank the 
USDA NASS for the CDL products and crop census database that serve as valuable reference in this research. We also thank Dr. Xiaolin Zhu at University of California - Davis for kindly providing the ESTARFM model for our study.

\section{References}

Allen. R., Hanuschak, G., \& Craig, M., 2002. History of remote sensing for crop acreage. www.nass.usda.gov/Surveys/Remotely_Sensed_Data_Crop_Acreage/index.asp (Last accessed on 5 December 2011). USDA-NASS, Washington, D.C.

Baffaut, C., Schuster, D., Heidenreich, L. K., Farrand, D. T., Bross, A. \& Benson, V., 2001. Miami Creek Watershed - water quality analysis. Available online: http://www.fapri.missouri.edu/wp-content/uploads/2015/04/FAPRI-MU-Report-01-01.pdf (last accessed on 6 May 2015). FAPRI-UMC Report \#01-01, May.

Blaschke, T., 2010. Object based image analysis for remote sensing. ISPRS Journal of Photogrammetry and Remote Sensing, 65, 2-16.

Boryan, C., Yang, Z., Mueller, R. \& Craig, M., 2011. Monitoring US agriculture: The US Department of Agriculture, National Agricultural Statistics Service, Cropland Data Layer Program. Geocarto International, 26, 341-358.

Farm Service Agency (FSA), USDA, 2011. Biomass crop assistance program - Project Area Number 1 implemented for western Missouri and eastern Kansas county biomass producers, Fact Sheet, May 2011.

Gao, F., Masek, J., Schwaller, M. \& Hall, F., 2006. On the blending of the Landsat and MODIS surface reflectance: Predicting daily Landsat surface reflectance. IEEE Transactions on Geoscience and Remote Sensing, 44, 2207-2218. 
Haralick, R. \& Shapiro, L., 1985. Image segmentation techniques. Computer Vision, Graphics, and Image Processing, 29, 100-132.

Hilker, T., Wulder, M. A., Coops, N. C., Linke, J., McDermid, G., Masek, J. et al., 2009. A new data fusion model for high spatial- and temporal-resolution mapping of forest based on Landsat and MODIS. Remote Sensing of Environment, 113, 1613-1627.

Hunt Jr., E. R., Li, L., Yilmaz, M. T. \& Jackson, T. J., 2011. Comparison of vegetation water contents derived from shortwave-infrared and passive-microwave sensors over central Iowa. Remote Sensing of Environment, 115, 2376-2383.

Kort, J., Collins, M. \& Ditsch, D., 1998. A review of soil erosion potential associated with biomass crops. Biomass and Bioenergy, 14, 351-359.

Li, Q., Wang, C., Zhang, B. \& Lu, L., 2015. Object-based crop classification with LandsatMODIS enhanced time-series data. Remote Sensing, 7(12), 16091-16107.

Lu, L., Guo, H., Wang, C. \& Li, Q., 2013. Assessment of the SeaWinds scatterometer for vegetation phenology monitoring across China. International Journal of Remote Sensing, 34, $5551-5568$.

McLaughlin, S. B., De La Torre Ugarte, D. G., Garten, C. T. Jr., Lynd, L. R., Sanderson M. A., Tolbert, V. R., \& Wolf, D. D., 2002. High-value renewable energy from prairie grasses. Environmental Science and Technology, 36, 2122-2129.

McLaughlin, S. B., \& Kszos, L. A., 2005. Development of switchgrass (panicum virgatum) as a bioenergy feedstock in the United States. Biomass and Bioenergy, 28, 515-535.

Missouri Department of Conservation (MDC), 2015. Conservation Atlas Area Summary: Bushwhacker Lake Conservation Area. Available online (last accessed on 31 August, 2015): http://mdc4.mdc.mo.gov/applications/moatlas/AreaSummaryPage.aspx?txtAreaID=7823. 
National Agricultural Statistics Service (NASS), USDA, 2010. Cropland Data Layer. Available at http://www.nass.usda.gov/research/Cropland/SARS1a.htm. Last accessed on 5 December, 2011.

Peña-Barragán, J. M., Ngugi, M. K., Plant, R. E., \& Six, J., 2011. Object-based crop identification using multiple vegetation indices, textural features and crop phenology. Remote Sensing of Environment, 115, 1301-1316.

Roy, D. P., Ju, J., Lewis, P., Schaaf, C., Gao, F., Hansen, M., et al., 2008. Multi-temporal MODIS-Landsat data fusion for relative radiometric normalization, gap filling, and prediction of Landsat data. Remote Sensing of Environment, 112, 3112-3130.

Savitzky, A. \& Golay, M. J. E., 1964. Smoothing and differentiation of data by simplified least squares procedures. Analytical Chemistry, 36,1627-1639.

Schill, S. R., 2011. USDA: 92.2 million acres of corn to be planted, up 5 percent. Ethanol Producer Magazine, March 31, 2011. Available online: http://ethanolproducer.com/articles/7632/usda-92-2-million-acres-of-corn-to-be-planted-up5-percent

Wang, C., Jamison, B., \& Spicci, A., 2010. Trajectory-based warm season grass mapping in Missouri prairies with multi-temporal ASTER imagery. Remote Sensing of Environment 114, 531-539.

Wang, C., Fritschi, F. B., \& Stacey, G., 2011. A geospatial approach to mapping energy crops in North American Tallgrass Prairie. Annuals of American Association of Geographers, 101, $741-751$. 
Wang, C., Hunt, E. R. Jr., Zhang, L., \& Guo, H., 2013. Spatial distributions of $\mathrm{C}_{3}$ and $\mathrm{C}_{4}$ grass functional types in the U.S. Great Plains and their dependency on interannual variability of climate. Remote Sensing of Environment, 138, 90-101.

Wang, C., Guo, H., Zhang, L., Liu, S., Qiu, Y. \& Sun, Z., 2015. Assessing phenological change and climatic control of alpine grasslands in the Tibetan Plateau with MODIS time series. International Journal of Biometeorology, 49, 11-23.

Weng, Q., P. Fu, and F. Gao, 2014. Generating daily land surface temperature at Landsat resolution by fusing Landsat and MODIS data. Remote Sensing of Environment, 145, 55-67.

Xian, G, Homer, C., \& Fry, J., 2009. Updating the 2001 National Land Cover Database land cover classification to 2006 by using Landsat imagery change detection methods. Remote Sensing of Environment, 113, 1133-1147.

Yuan, F., C. Wang and M. Mitchell, 2014. Spatial patterns of land surface phenology relative to monthly climate variations: US Great plains. GIScience and Remote Sensing, 51(1):30-50.

Zhong, C., Wang, C., \& Wu, C., 2015. MODIS-based fractional crop mapping in the U.S. Midwest with spatially constrained phenological mixture analysis. Remote Sensing, 7, 512529.

Zhu, Z., Chen, J., Gao, F., Chen, Z., \& Masek, J. G., 2010. An enhanced spatial and temporal adaptive reflectance fusion model for complex heterogeneous regions. Remote Sensing of Environment, 114, 2610-2623.

Zurita-Milla, R., Kaiser, G., Clevers, J. G. P. W., Schneider, W., \& Schaepman, M. E., 2009. Downscaling time series of MERIS full resolution data to monitor vegetation seasonal dynamics. Environmental Monitoring and Assessment, 113, 1874-1885. 